\title{
Actinomycetes as Tools for Biotransformations of Lignans
}

\author{
Debora Noma Okamoto ${ }^{1}$, Vitor Baptista Ferrari ${ }^{1}$, João Henrique Ghilardi Lago ${ }^{2}$, Itamar Soares de Melo ${ }^{3}$, \\ Suzan Pantaroto Vasconcellos ${ }^{1}$
}

${ }^{1}$ Department of Pharmaceutical Sciences, Universidade Federal de SãoPaulo (UNIFESP), R. São Nicolau, 210 - Diadema, SP, Brazil, Zip Code $09913-030$.

${ }^{2}$ Center of Human and Natural Sciences, Federal University of ABC, Santo André, SP, Brazil, Zip Code 09210-580.

${ }^{3}$ Laboratory of Environmental Microbiology, Brazilian Agricultural Research Corporation, EMBRAPA Environment, Jaguariúna, Brazil, Zip Code 13820-000.

Received: October 12, 2017; Published: October 17, 2017

*Corresponding author: Suzan Pantaroto de Vasconcellos, Department of PharmaceuticalSciences, Universidade Federal de SãoPaulo (UNIFESP), R. São Nicolau, 210 - Diadema, SP, Brazil, Zip Code 09913-030,Email: suzan.pantaroto@unifesp.br

\section{Opinion}

The current demands for novel and sustainable biotechnological processes, including new microbial enzymes with industrial potential are constantly required. As a form to address the growing need for industrially relevant enzymes, functional screenings of microorganisms and/or (meta)genome mining techniques have emerged as powerful strategies for the identification of promising enzymes to novel or improved industrial processes [1]. Once enzymes have been well characterized, they can be produced, studied, and engineered about their biocatalytic, including possible synergistic activities in multiple protein cocktails. Currently, there is an increased interest in exploring and exploiting microbial enzymes for selective degradation of plant biomass. The efforts are concentrated on the bioconversion of lingo-cellulosic material. While ample enzymes are nowadays available for the degradation and modification of the polysaccharide content of plant biomass, there is a need for effective lignin degrading enzymes.

Focus on novel ligninolytic enzymes from microbial lignindegrading systems can be valuable biocatalytic tools for the valorisation lignocellulosic material, as energetic substrates for bio-products obtaining. Biocatalysis refers to the use of whole cells or enzymes to catalyze reactions or transformations can promote the generation of numerous human needs [2].

One of the most recently microbial groups explored in this area is actinobacteria, known about their special abilities to produce diverse bioactive compounds, including enzymes with multiple biotechnological applications. Due to its ability to produce secondary metabolites with widespread industrial applications, actinomycetes have attracted the attention of many research groups in the world [3].

Adapted to many environmental conditions, actinobacteria are particularly promising, since this group is a potential producer of antimicrobial compounds, enzyme inhibitors, immuno-modifiers, enzymes and growth promoting substances for plants and animals [4]. Additionally these bacteria can also participate in the degradation processes of recalcitrant organic matter, contributing to the ecological balance do carbon in the planet.

Lignin, as molecular compound, comes from the oxidative polymerization of hydroxycinnamic alcohol derivatives [5]. The term lignocellulose is related to the bound of cellulosic material and the phenolic polymer by ferrul oil bonds [6]. Davin et al. (2008) [7] conducted extensive reviews of various aspects of lignin and lignan formation, including a detailed biochemical evaluation of reactions by random or controlled coupling of 4-hydroxyphenyl $(H)$, guaiacyl $(G)$ and siringuil $(S)$, as well monolignol derivatives. In this sense, due to the economic value added in the production of wood and biofuels, lignin biosynthesis, as well as its manipulation, has been described as the target of some research works [8]. Enzymes that lead to the formation of monomers with different compositions, resulting in different proportions of guaiacyl and siringuil units, involving gene and mutation studies [9-11]. In addition, informations about the enzymatic reactions involved in the formation of lignans from coniferous alcohols is still limited [5].

In this context, lignocellulolytic enzymes from actinobacteria are one of the most explored for their application in industries that use lingo-cellulose as raw material. In addition to cellulose, lignin is also considered as one of the most abundant polymers at Earth. Lignin, suber in and condensed tannins are polymers composed by phenyl-propanoids that can contribute significantly to the stability and robustness of gymnosperms and angiosperms, from mechanical or environmental damage, such as pruning or drying [7].

While in the past, it was thought that only (white-rot) fungi were responsible for the degradation of lignin, it is becoming clear that also bacteria can play an important role in lignin degradation [12]. The main bacterial enzyme actors in lignin degradation seem to be laccases and a recently identified family of heme-containing peroxidases known as dye-decolorizing peroxidases (DyPs, EC 1.11.1.19] [13,14]. These enzymes form a distinct group of hemecontaining peroxidases and seem to offer attractive catalytic 
properties for biotechnological purposes, including ligninolytic abilities [15]. Except for these bacterial peroxidases, laccases also can be potent lignin-modifying enzymes. These oxidoreductases act on various polyphenols which form the core of lignocellulosic material $[16,17]$. Laccases are classified as multicopper oxidases, with low substrate specificity, which allows their activity under a large scope of organic compounds. Laccases typically contain four copper atoms to support catalysis. Laccases from actinomycetes were also already described, including Streptomyces griseus, $S$. cyaneus, S. coelicolor, S. ipomoea, S. Sviceus and Thermobifida fusca. These proteins were found to represent so-called small laccases, containing two domains linked to copper atoms [18,19]. Genes from diverse lignocellulolytic actinomycete strains have been described, cloned and expressed in Escherichia coli [20-22]. Saini et al. (2015) [23] reported about a thermo-alkali stable laccase from Thermobifida fusca, which could promote oxidation of 2,6-dimethyl phenylalanine and p-aminophenol [24]. While some reports show that several bacterial peroxidases and laccases have been reported in literature, the number of available and well-characterized laccases and Dyp-type peroxidases is very limited.

In this sense, studies about lignans and their pharmacological properties have been gaining increased relevance, involving investigations on their cytostatic, antitumor, as well as antiparasitary activities. In this way, enzymatically directed reactions, promoting improvement of regal and diastereo-selectivity, for the desired products, have become elegant tools and extremely relevant in the study of lignans. In order to evaluate the effect of the microorganisms on the biotransformation of lignans, some studies have been conducted [5,25-28].

All of these allied to emerging issues, non-profit, over-thecounter potential efficient medicines, treatment of neglected diseases, sustainable production of fuels, making the use of viable technologies, low cost and reuse of plant biomass. In this way, more investigations are needed in order to converge with the evaluation of the same substrates to the microbial metabolism, like some phenylpropanoids isolated from Necthandra neucantha, belonging to the family Lauraceae [29]. Such a multidisciplinary characteristic of a project that is being conducted by our research group, we are aiming the pharmacological evaluation of the biotransformation of phenylpropanoids with historical parasitic activities, by actinobacteria isolated from distinct Brazilian environmental habitats. Conventional methods using plants to produce compounds are still considered as effective, but they imply in low concentration of the desired compounds and high dependence on agricultural productivity, which involves classical risk factors, including climatic conditions and plant pathogens [30].

Previous results from our group and partnerships, demonstrated that some actinomycetes can be able to promote the bioconversion of lignin compounds, motivating deep investigations about the enzymatic systems that are involved, as well as the characterization of reaction products. In terms of bioenergy view, the conducted study is innovating in the use of non described compounds (lignans) [29], as model substrate to evaluate ligninolytic abilities of microbial strains. At the clinic view, it is possible to verify new possibilities to biotransformed phenylpropanoids with improved activities.

\section{References}

1. Subramaniyan S, Prema P (2002) Biotechnology of Microbial Xylanases: Enzymology, Molecular Biology, and Application. Crit Rev Biotechnol 22(1): 33-64.

2. Arroy M, Acebal C, De la Mata I (2014) Biocatálisis y biotecnologia. Arbor 190(768): a156.

3. Chavan DV, Mulaje SS, Mohalkar RY (2013) A Review on actinomycetes and their biotechnological applications. Int J Pharm Sci Res 4: 17301742.

4. Goodfellow M, and Williams ST (1983) Ecology of actinomycetes. Annu Rev Microbiol 37: 189-216.

5. Vogt T (2010) Phenylpropanoid biosynthesis. Mol Plant 3(1): 2-20.

6. Burr SJ, Fry SC (2009) Feruloylated arabinoxylans are oxidatively cross-linked by extracellular maize peroxidase but not by horseradish peroxidase. Mol Plant 2(5): 883-892

7. Davin LB, Jourdes M, Patten AM, Kim KW, Vassão DG, et al. (2008) Dissection of lignin macromolecular configuration and assembly: Comparison to related biochemical processes in allyl/propenyl phenol and lignan biosynthesis. Nat Prod Rep 25(6): 1015-1190.

8. Rubin EM (2008) Genomics of cellulosic biofuels. Nature 454: 841-845

9. Anterola AM, Lewis NG (2002) Trends in lignin modification: A comprehensive analysis of the effects of genetic manipulations/ mutations on lignification and vascular integrity. Phytochemistry 61(3): 221-294.

10. Dixon RA, Reddy MSS (2003) Biosynthesis of monolignols. Genomic and reverse genetic approaches in Phytochemistry Reviews 2: 289-306.

11. Vanholme R, Morreel K, Ralph J, Boerjan W (2008) Lignin engineering Curr Opin. Plant Biol 11(3): 278-285.

12. De Gonzalo G, Colpa DI, Habib MHM, Fraaije MW (2016) Bacterial enzymes involved in lignin degradation. J Biotechnol 236: 110-119.

13. Sugano Y, Muramatsu R, Ichiyanagi A, Sato T, Shoda M (2007) DyP, a unique dye-decolorizing peroxidase, represents a novel heme peroxidase family: ASP171 replaces the distal histidine of classical peroxidases. J Biol Chem 282(50): 36652-36658.

14. Salvachúa D, Prieto A, Martínez ÁT, Martínez MJ (2013) Characterization of a novel dye-decolorizing peroxidase (DyP)-type enzyme from Irpex lacteus and its application in enzymatic hydrolysis of wheat straw. App Environ Microbiol 79(14): 4316-4324.

15. Liers C, Aranda E, Strittmatter E, Piontek K, Plattner DA, et al. (2014) Phenol oxidation by DyP-type peroxidases in comparison to fungal and plant peroxidases. J Mol Catal B Enzym 103: 41-46.

16. Abdel-Hamid AM, Solbiati JO, Cann IKO (2013) Insights into Lignin Degradation and its Potential Industrial Applications. Adv Appl Microbiol 82: 1-28

17. Madhavi V, Lele SS (2009) Laccase: Properties and applications. BioResources 4(4): 1694-1717.

18. Alves T, Fernandes R, Batista Da Silveira W, Lopes Passos FM, Zucchi TD, et al. (2014) Laccases from Actinobacteria-What We Have and What to Expect. In Advances in Microbiology 4(6): 285-296.

19. Lu L, Zeng G, Fan C, Zhang J, Chen A, et al. (2014) Diversity of twodomain laccase-like multicopper oxidase genes in Streptomyces spp.: Identification of genes potentially involved in extracellular activities and lignocellulose degradation during composting of agricultural waste. Appl Environ Microbiol 80(11): 3305-3314.

20. Li N, Shi P, Yang P, Wang Y, Luo H, et al. (2009) Cloning, expression, and characterization of a new streptomyces sp. S27 xylanase for which 
xylobiose is the main hydrolysis product. Appl Biochem Biotechnol 159(2): 521-531.

21. Dubé E, Shareck F, Hurtubise Y, Daneault C, Beauregard M (2008) Homologous cloning, expression, and characterisation of a laccase from Streptomyces coelicolor and enzymatic decolourisation of an indigo dye. Appl Microbiol Biotechnol 79(4): 597-603.

22. Suzuki T, Endo K, ITO M, Tsujibo H, Miyamoto K, et al. (2003) A Thermostable Laccase from Streptomyces lavendulae REN-7: Purification, Characterization, Nucleotide Sequence, and Expression. Biosci. Biotechnol Biochem 67(10): 2167-2175

23. Saini A, Aggarwal NK, Sharma A, Yadav A (2015) Actinomycetes: A Source of Lignocellulolytic Enzymes. Enzyme Res.

24. Chen CY, Hsieh ZS, Cheepudom J, Yang CH, Meng M (2013) A 24.7-kDa copper-containing oxidase, secreted by Thermobifida fusca, significantly increasing the xylanase/cellulase-catalyzed hydrolysis of sugarcane bagasse. Appl Microbiol Biotechnol 97(20): 8977-8986.

25. Nakatsubo T, Mizutani M, Suzuki S, Hattori T, Umezawa T (2008) Characterization of Arabidopsis thaliana pinoresinol reductase, a new type of enzyme involved in lignan biosynthesis. J Biol Chem 283(23): 15550-15557.
26. Messiano GB, da Silva T, Nascimento IR, Lopes LMX (2009) Biosynthesis of antimalarial lignans from Holostylis reniformis. Phytochemistry 70: 590-596.

27. Han D, Kurusarttra S, Ryu JY, Kanaly RA, Hur HG (2012) Production of natural fragrance aromatic acids by coexpression of trans-anethole oxygenase and p-anisaldehyde dehydrogenase genes of Pseudomonas putida JYR-1 in Escherichia coli. J Agric Food Chem 60(48): 1197211979.

28. Han D, Sadowsky MJ, Chong Y, Hur HG (2013) Characterization of a Selfsufficient Trans-Anethole Oxygenase from Pseudomonas putida JYR-1.

29. Costa-Silva TA Da, Grecco SS, De Sousa FS, Lago JHG, Martins EGA, et al. (2015) Immunomodulatory and Antileishmanial Activity of Phenylpropanoid Dimers Isolated from Nectandra leucantha. J Nat Prod 78(4): 653-657.

30. Longo MA, Sanromán MA (2006) Production of food aroma compounds: Microbial and enzymatic methodologies. Food Technol Biotechnol 44: 335-353.

\begin{tabular}{ll} 
BIOMEDICAL & Assets of Publishing with us \\
- GlobeARCHES & - Immediate, unrestricted online access \\
\hline
\end{tabular}

